\title{
An In Silico Approach towards the Prediction of Druglikeness Properties of Inhibitors of Plasminogen Activator Inhibitor 1
}

\author{
Umadevi Subramanian, ${ }^{1}$ Ashok Sivapunniyam, ${ }^{1}$ \\ Ayyasamy Pudukadu Munusamy, ${ }^{2}$ and Rajakumar Sundaram ${ }^{1}$ \\ ${ }^{1}$ Department of Marine Biotechnology, Bharathidasan University, Tiruchirappalli, Tamil Nadu 620 024, India
}

${ }^{2}$ Department of Microbiology, Periyar University, Salem, Tamil Nadu 636 011, India

Correspondence should be addressed to Rajakumar Sundaram; kodairaj@gmail.com

Received 6 June 2014; Accepted 27 November 2014; Published 15 December 2014

Academic Editor: Stavros J. Hamodrakas

Copyright ( 2014 Umadevi Subramanian et al. This is an open access article distributed under the Creative Commons Attribution License, which permits unrestricted use, distribution, and reproduction in any medium, provided the original work is properly cited.

\begin{abstract}
Diabetic retinopathy is the leading cause of blindness worldwide. It is caused by the abnormal growth of the retinal blood vessels. Plasminogen activator inhibitorl (PAI1) is the key growth factor and the inhibition of PAIl can reduce the angiogenesis. In this study, currently available inhibitors are taken and tested for the toxicity, binding affinity, and bioactivities of the compounds by in silico approach. Five toxic free inhibitors were identified, among which $\mathrm{N}$-acetyl-D-glucosamine shows the significant binding affinity and two of the molecules are having the better bioactivity properties. The molecular optimization of 2-(acetylamino)-2deoxy-A-D-glucopyranose and alpha-L-fucose can be used for the treatment of diabetic retinopathy.
\end{abstract}

\section{Introduction}

Almost half of the diabetes mellitus patients have the high risk of diabetic retinopathy. Worldwide, 17 million people are affected with proliferative diabetic retinopathy [1]. In diabetic patients, the sugar molecules accumulate in retinal blood vessels and damage them; sometimes the molecules block the vessels. Due to this, supply of oxygen and other nutrition to the retina will be reduced; this condition is called ischemia. To overcome this situation, the retina will produce new blood vessels, the process known as neovascularization. But the newly produced vessels are abnormal and fragile; they leak fluid into macula, a part of the retina which is responsible for clear central vision, and cause vision loss [2]. Presently, laser treatment is in use to treat retinopathy, but it leads to peripheral vision loss as it burns the retina. The alternative strategy is to control the expression of the growth factors which induce angiogenesis.

Plasminogen activator inhibitorl (PAIl) is one of the growth factors responsible for neovascularization in diabetic patients. After ischemia, it is secreted from endothelial cells
[3]. It is reported that inhibition of PAIl will lead to 53\% reduction in retinal angiogenesis and prevent tumor invasion and vascularization $[4,5]$. In this study, an attempt was made to identify the better therapeutic inhibitor for PAIl.

\section{Materials and Methods}

2.1. PAI1 Structure Retrieval and Active Site Identification. The 3D structure of PAIl was retrieved from Protein Data Bank (PDB) [6]. To identify the active site of the protein, the depth and solvent accessible surface area (SASA) were computed and based on that the probability values are assigned to each amino acid using DEPTH server [7]. The residue with high depth and SASA values are likely to form the active site.

2.2. Identification of Inhibitors. The inhibitor compounds (used as ligands in docking studies) so far identified against PAI1 protein were collected from various databases, namely, Human Metabolome Database (HMDB) [8], DrugBank [9], Pharmacogenomic knowledgebase (PharmaGKB) [10], and PDB. 
TABLE 1: Ligand molecules of PAI1 protein.

\begin{tabular}{ll}
\hline Database & Inhibitor molecules \\
\hline HMDB & Atorvastatin, dimethyl sulfoxide, and simvastatin. \\
DrugBank & Troglitazone. \\
PharmaGKB & $\begin{array}{l}\text { Antidepressants (including amitriptyline hydrochloride, amoxapine, clomipramine hydrochloride, and desipramine } \\
\text { hydrochloride), citalopram, and fluoxetine. }\end{array}$ \\
& $\begin{array}{l}\text { 2,5-Dihydroxy-3-undecyclohexa-2,5-diene-1,4,-dione; 1,2-ethanediol; beta-D-mannose; alpha-L-fucose; } \\
\text { PDB }\end{array}$ \\
\end{tabular}

2.3. Toxicity Screening. The collected ligand compounds were screened for toxicity using the online server ToxPredict (http://apps.ideaconsult.net:8080/ToxPredict). It estimates the hazard of chemical structures mainly based on Lipinski's rule and Cramer's rule. The molecules which are having the hydrogen donors $\leq 5$, hydrogen bond acceptor $\leq$ 10 , molecular mass $\leq 500$ daltons, and $\log P \leq 5$ are likely to obey Lipinski's rule, and Cramer's rule classifies the chemical compounds into three classes based on the 33 metabolic activities. The compounds belonging to class I are of low order of toxicity, class II are more innocuous than the other two classes, and class III are of significant toxicity.

2.4. Docking. Docking calculations were carried out using interactive molecular graphics programs ArgusLab [11] and PatchDock [12]. Ligand was placed on a search point in the binding site which was calculated by DEPTH server; a set of diverse and energetically favorable rotations was created. In ArgusDock, exhaustive search methods for flexible ligand docking were used to calculate the binding energy. PatchDock algorithm divided the surface representation of the molecules into concave, convex, and flat patches. Then, complementary patches were matched in order to generate candidate transformations and evaluated by scoring functions. The results were visualized by Molegro Molecular Viewer (http://www.molegro.com).

2.5. Bioactivity Prediction. The bioactivities of the biologically significant ligands were predicted by OSIRIS Property Explorer (http://www.organicchemistry.org/prog/peo/). The calculations were originally optimized on training sets of more than 5000 compounds with measured $\log P$ values and more than 2000 compounds with measured $\log S$ values. The drug score ranges between 0 and 1 .

\section{Results and Discussion}

3.1. PAI1 Structure Retrieval and Identification of Active Site. There are 9 structures with IDs 3LW2, 3Q02, 3R4L, 1C5G, 1DB2, 1DVN, 1DVM, 1LJ5, and 1B3K which are available for PAI1 in PDB, among which the structure IB3K, which consists of 4 chains, was selected as it is in active form and is free from being bound with other molecules. The active site region was identified, represented in Figure 1, and the amino acid composition of the active site is represented in Figure 2.

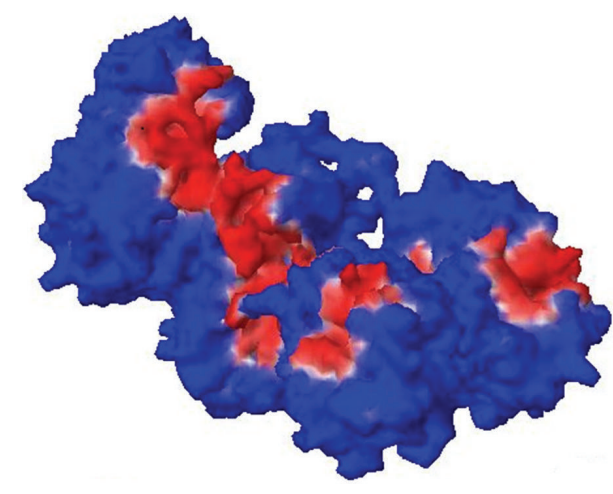

FIGURE 1: Active site region of the protein is red in colour.

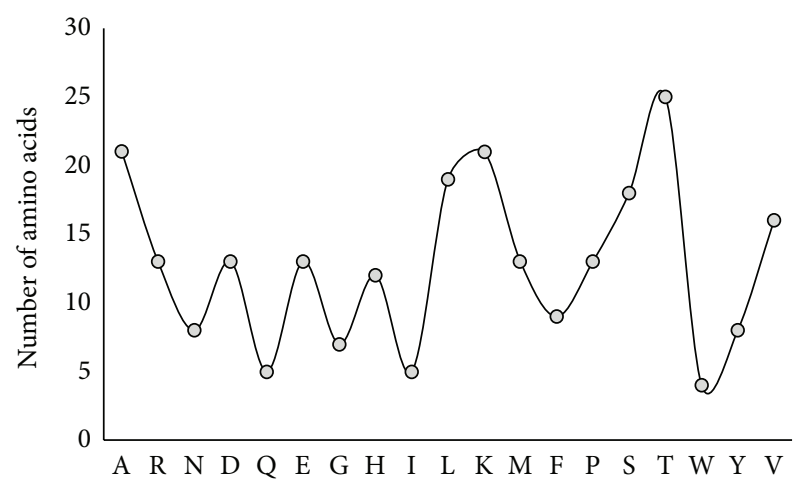

FIGURE 2: Amino acid composition of active site of PAIl.

3.2. Identified Ligand Compounds for PAI1. The inhibitors to the protein of our interest are listed in Table 1.

3.3. Toxicity Prediction. The toxicity of the molecules, based on Lipinski's rule and Cramer's rule whether they induce carcinogen or eye irritation, is represented in Table 2.

Based on the lower toxicity, the ligands were filtered for further studies; the molecules include 2-acetylamino2-deoxy-A-D-glucopyranose, alpha-L-fucose, beta-D-mannose, $\mathrm{N}$-acetyl-D-glucosamine, and ribose.

3.4. Docking Study of PAII with Selected Ligand Molecules. The graphical representations of the docking of PAI1 protein with 2-acetylamino-2-deoxy-A-D-glucopyranose, alphaL-fucose, beta-D-mannose, N-acetyl-D-glucosamine, and 
TABLE 2: Toxicity prediction of the inhibitors of PAI1.

\begin{tabular}{|c|c|c|c|c|}
\hline Ligand molecule & Obey Lipinski’s rule? & Cramer's rule & Carcinogen & Eye irritation \\
\hline Troglitazone & Yes & Class III & No & No \\
\hline Dimethyl sulfoxide & Yes & Class III & No & No \\
\hline Atorvastatin & No & Class III & No & No \\
\hline Simvastatin & Yes & Class III & No & No \\
\hline Citalopram & Yes & Class III & No & No \\
\hline Fluoxetine & Yes & Class III & No & No \\
\hline 2,5,Dihydroxy-3-undecyciohexa-2,5-diene-1,4,dione & No & Class III & No & No \\
\hline 1,2-Ethanediol & Yes & Class I & No & Yes \\
\hline Beta-D-mannose & Yes & Class I & No & No \\
\hline Alpha-L-fucose & Yes & Class I & No & No \\
\hline N-Acetyl-D-glucosamine & Yes & Class I & No & No \\
\hline 2-(Acetylamino)-2-deoxy-A-D-glucopyranose & Yes & Class I & No & No \\
\hline Ribose & Yes & Class I & No & No \\
\hline Acetic acid & Yes & Class III & No & No \\
\hline Amitriptyline hydroxychloride & No & Class III & No & No \\
\hline Amoxapine & Yes & Class III & No & No \\
\hline Clomipramine hydrochloride & Yes & Class III & No & No \\
\hline Desipramine hydrochloride & Yes & Class III & No & No \\
\hline
\end{tabular}

TABLE 3: Binding energy of 2-acetylamino-2-deoxy-A-D-glucopyranose with PAIl.

\begin{tabular}{lccc}
\hline Bond & \multicolumn{2}{c}{ Energy } & Residues involved \\
\hline Hydrogen & $-2.5(\mathrm{kcal} / \mathrm{mol})$ & $2.64532 \AA$ (length) & Glu 1387 \\
Hydrogen & $-2.5(\mathrm{kcal} / \mathrm{mol})$ & $2.99992 \AA$ (length) & Val 1388 \\
Hydrogen & $-2.5(\mathrm{kcal} / \mathrm{mol})$ & $2.69638 \AA$ (length) & Ser 1131 \\
Hydrogen & -0.835562 & $3.43289 \AA$ (length) & Ser 1131 \\
Hydrogen & $(\mathrm{kcal} / \mathrm{mol})$ & $2.72334 \AA$ (length) & - \\
\hline Hydrogen (nondirectional) & $-2.5(\mathrm{kcal} / \mathrm{mol})$ & $-13.551(\mathrm{kcal} / \mathrm{mol})$ & Asp 948, Gly 949, Thr 945, Thr 946, Thr \\
\hline \multirow{2}{*}{ Steric } & $-71.96(\mathrm{kcal} / \mathrm{mol})(\mathrm{by} \mathrm{PLP})$ & 951, Ala 1130, Asn 1135, Asp 1389, Lys 1392, \\
& $-24.70(\mathrm{kcal} / \mathrm{mol})(\mathrm{by} \mathrm{LJ16-6)}$ & Pro 1393, Thr 1386, Val 1127, Val 1136 \\
\hline
\end{tabular}

TABLE 4: Binding energy of alpha-L-fucose with PAIl.

\begin{tabular}{|c|c|c|c|}
\hline Bond & \multicolumn{2}{|c|}{ Energy } & Residues involved \\
\hline Hydrogen & $-2.50(\mathrm{kcal} / \mathrm{mol})$ & 2.84262 Å (length) & Val 1388 \\
\hline Hydrogen & $-0.91(\mathrm{kcal} / \mathrm{mol})$ & 3.41776 Å (length) & Ser 1131 \\
\hline Hydrogen (nondirectional) & \multicolumn{2}{|c|}{$-4.04(\mathrm{kcal} / \mathrm{mol})$} & - \\
\hline Steric & \multicolumn{2}{|c|}{$\begin{array}{l}-52.65(\mathrm{kcal} / \mathrm{mol})(\text { by PLP) } \\
-17.65(\mathrm{kcal} / \mathrm{mol})(\text { by LJ16-6) }\end{array}$} & $\begin{array}{l}\text { Asp 948, Gly 949, Pro 947, Thr 945, Thr } \\
\text { 946, Tyr 951, Ala 1130, Asp 1389, Glu 1387, } \\
\text { Pro 1393, Thr 1386, Val 1127, Val } 1136\end{array}$ \\
\hline
\end{tabular}

ribose are in Figures 3, 4, 5, 6, and 7; yellow lines represent hydrogen bonds, pale blue dots represent hydrogen atom acceptors, yellow dots represent hydrogen atom donors, red dots represent positive ions, and dark blue dots represent negative ions. The corresponding binding energy values are presented in Tables 3, 4, 5, 6, and 7 and the overall energy of each inhibitor binding with PAI1 is in Table 8 .
3.5. Bioactivity Properties. The bioactivity of the ligands which are toxic free and having biologically significant binding affinity is represented in Table 9.

Among the presently identified inhibitors against PAIl, only five of them, namely, 1,2-ethanediol, beta-D-mannose, alpha-L-fucose, N-acetyl-D-glucosamine, and 2-(acetylamino)-2-deoxy-A-D-glucopyranose, come under class I of 
TABLE 5: Binding energy of beta-D-mannose with PAI1.

\begin{tabular}{|c|c|c|c|}
\hline Bond & \multicolumn{2}{|c|}{ Energy } & Residues involved \\
\hline Hydrogen & $-1.34(\mathrm{kcal} / \mathrm{mol})$ & $3.05 \AA$ (length) & Glu 1387 \\
\hline Hydrogen & $-0.23(\mathrm{kcal} / \mathrm{mol})$ & 3.51 Å (length) & Glu 1387 \\
\hline Hydrogen & $-2.45(\mathrm{kcal} / \mathrm{mol})$ & $3.11 \AA$ (length) & Val 1136 \\
\hline Hydrogen & $-1.78(\mathrm{kcal} / \mathrm{mol})$ & $3.24 \AA$ (length) & Thr 945 \\
\hline Hydrogen & $-2.50(\mathrm{kcal} / \mathrm{mol})$ & $2.86 \AA$ (length) & Tyr 951 \\
\hline Hydrogen (nondirectional) & \multicolumn{2}{|c|}{$-15.91(\mathrm{kcal} / \mathrm{mol})$} & - \\
\hline Steric & \multicolumn{2}{|c|}{$\begin{array}{c}-35.10(\mathrm{kcal} / \mathrm{mol})(\text { by PLP) } \\
-445.37(\mathrm{kcal} / \mathrm{mol})(\text { by LJ16-6) }\end{array}$} & $\begin{array}{c}\text { Asp 948, Gly 949, His 950, Thr 946, Ala } \\
\text { 1130, Arg 1134, Asn 1135, Asp 1389, Gln } \\
\text { 1126, Lys 1392, Pro 1393, Thr 1386, Val } \\
\text { 1127, Val 1388 }\end{array}$ \\
\hline
\end{tabular}

TABLE 6: Binding energy of N-acetyl-D-glucosamine with PAI1.

\begin{tabular}{|c|c|c|c|}
\hline Bond & \multicolumn{2}{|c|}{ Energy } & Residues involved \\
\hline Hydrogen & $-2.50(\mathrm{kcal} / \mathrm{mol})$ & $2.85 \AA$ (length) & Val 1127 \\
\hline Hydrogen & $-0.21(\mathrm{kcal} / \mathrm{mol})$ & $3.55 \AA$ (length) & Ser 1131 \\
\hline Hydrogen & $-2.50(\mathrm{kcal} / \mathrm{mol})$ & $3.02 \AA$ (length) & Ser 1131 \\
\hline Hydrogen & $-0.90(\mathrm{kcal} / \mathrm{mol})$ & $3.42 \AA$ (length) & Tyr 951 \\
\hline Hydrogen & $-2.50(\mathrm{kcal} / \mathrm{mol})$ & $2.84 \AA$ (length) & Pro 947 \\
\hline Hydrogen (nondirectional) & \multicolumn{2}{|c|}{$-14.54(\mathrm{kcal} / \mathrm{mol})$} & - \\
\hline Steric & \multicolumn{2}{|c|}{$\begin{array}{l}-44.44(\mathrm{kcal} / \mathrm{mol})(\text { by PLP) } \\
13.40(\mathrm{kcal} / \mathrm{mol})(\text { by LJ16-6) }\end{array}$} & $\begin{array}{c}\text { Asp 948, Gly 949, His 950, Thr 945, Thr } \\
\text { 946, Ala 1130, Asn 1135, Asp 1389, Gln } \\
\text { 1126, Glu 1387, Lys 1392, Pro 1393, Thr } \\
\text { 1386, Val 1136, Val } 1388\end{array}$ \\
\hline
\end{tabular}

TABLE 7: Binding energy of ribose with PAI1.

\begin{tabular}{|c|c|c|c|}
\hline Bond & \multicolumn{2}{|c|}{ Energy } & Residues involved \\
\hline Hydrogen & $-1.02(\mathrm{kcal} / \mathrm{mol})$ & $3.39 \AA$ (length) & Val 1127 \\
\hline Hydrogen & $-2.30(\mathrm{kcal} / \mathrm{mol})$ & $2.57 \AA$ (length) & Ser 1131 \\
\hline Hydrogen & $-2.49(\mathrm{kcal} / \mathrm{mol})$ & $2.59 \AA$ (length) & Ser 1131 \\
\hline Hydrogen (nondirectional) & \multicolumn{2}{|c|}{$-5.82(\mathrm{kcal} / \mathrm{mol})$} & - \\
\hline Steric & \multicolumn{2}{|c|}{$\begin{array}{l}-46.01(\mathrm{kcal} / \mathrm{mol})(\text { by PLP) } \\
-17.31(\mathrm{kcal} / \mathrm{mol})(\text { by LJ16-6) }\end{array}$} & $\begin{array}{c}\text { Asp 948, Gly 949, Pro 947, Thr 945, Thr } \\
\text { 946, Tyr 951, Ala 1130, Asp 1389, Glu 1387, } \\
\text { Thr 1386, Val 1136, Val } 1388\end{array}$ \\
\hline
\end{tabular}

TABLE 8: The overall binding affinity of ligands with PAIl.

\begin{tabular}{lcc}
\hline Ligand molecule & $\begin{array}{c}\text { Binding energy } \\
(\mathrm{kcal} / \mathrm{mol})\end{array}$ & $\begin{array}{c}\text { Area covered } \\
(\AA)\end{array}$ \\
\hline $\begin{array}{l}\text { N-Acetyl-D-glucosamine } \\
\text { 2-Acetylamino-2-deoxy-A-D- }\end{array}$ & -7.83 & 386.10 \\
glucopyranose & -6.03 & 402.30 \\
Beta-D-mannose & -6.00 & 508.40 \\
Alpha-L-fucose & -5.43 & 283.50 \\
Ribose & -5.13 & 251.00 \\
\hline
\end{tabular}

Cramer's rule. As 1,2-ethanediol causes the irritation in eye, it is excluded from the study. The remaining ligand compounds are used for further study.
The docking results showed that $\mathrm{N}$-acetyl-D-glucosamine is highly biologically significant followed by 2-(acetylamino)2-deoxy-A-D-glucopyranose, beta-D-mannose, alpha-L-fucose, and ribose in decreasing order. The above five molecules are toxic free and can bind with PAIl, but the bioactivities of the compounds revealed that 2-(acetylamino)-2-deoxy-A-Dglucopyranose and alpha-L-fucose are having the property of druglikeness at moderate level; the rest cannot be used for the purpose of drug.

\section{Conclusion}

For the known inhibitors of PAI1, toxicity, binding affinity, and bioactivity were predicted computationally. There were five molecules identified; moreover they have the feasible 
Table 9: Bioactivity of the selected ligands of PAIl.

\begin{tabular}{|c|c|c|c|c|c|}
\hline Ligand & $c \log P$ & Solubility & Molecular weight & Druglikeness & Drug score \\
\hline 2-Acetylamino-2-deoxy-A-D-glucopyranose & -1.63 & -0.15 & 191.01 & -0.50 & 0.67 \\
\hline Alpha-L-fucose & -1.63 & -0.15 & 101.00 & -0.56 & 0.67 \\
\hline Beta-D-mannose & -3.5 & 0.42 & 312.00 & -5.08 & 0.38 \\
\hline N-Acetyl-D-glucosamine & -2.3 & -0.02 & 221.00 & -3.05 & 0.5 \\
\hline Ribose & -1.3 & -0.06 & 134.00 & -5.68 & 0.4 \\
\hline
\end{tabular}

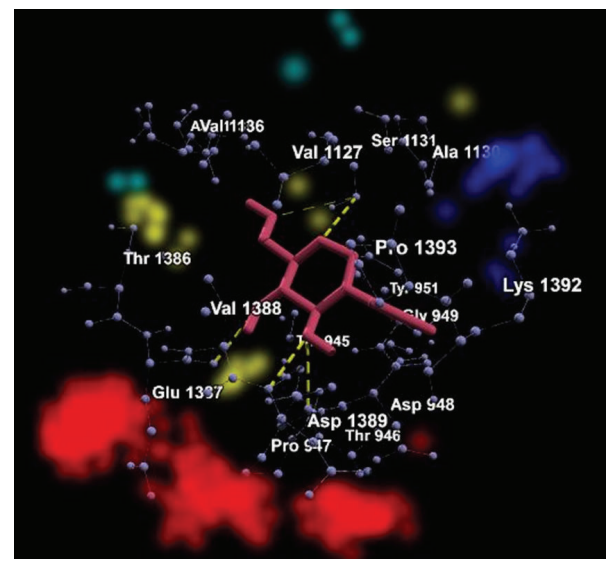

Figure 3: Binding of 2-acetylamino-2-deoxy-A-D-glucopyranose with PAI1.

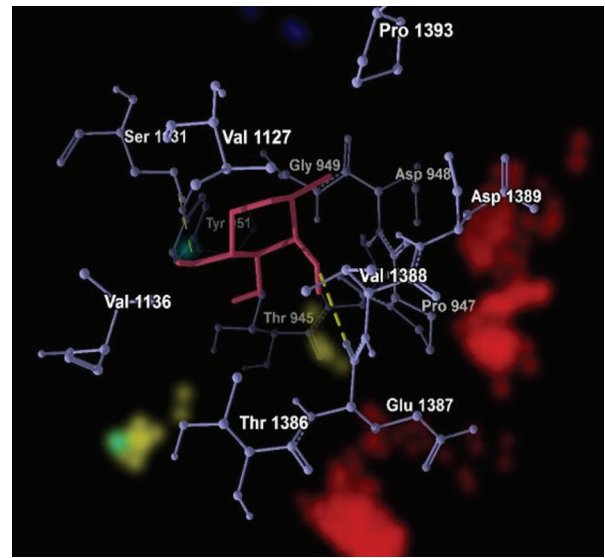

FIgure 4: Binding of alpha-L-fucose with PAI1.

binding affinity with PAIl as well. As the molecular weight of $\mathrm{N}$-acetyl-D-glucosamine and beta-D-mannose is higher and $c \log P$ value is higher for ribose, there is a least priority to these compounds to be used as drug. The molecules 2-(acetylamino)-2-deoxy-A-D-glucopyranose and alpha-Lfucose were identified as better therapeutic inhibitors to PAI1 than other molecules used in this study. Due to the toxic free nature and significant binding energy, this study can be extended at clinical level. For the efficient and quick treatment level, they should be structurally optimized as the drug score of the identified two molecules was moderate.

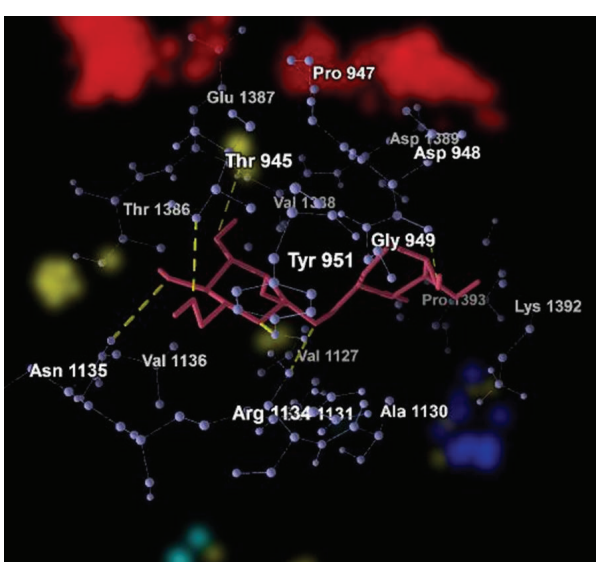

FIgURE 5: Binding of beta-D-mannose with PAIl.

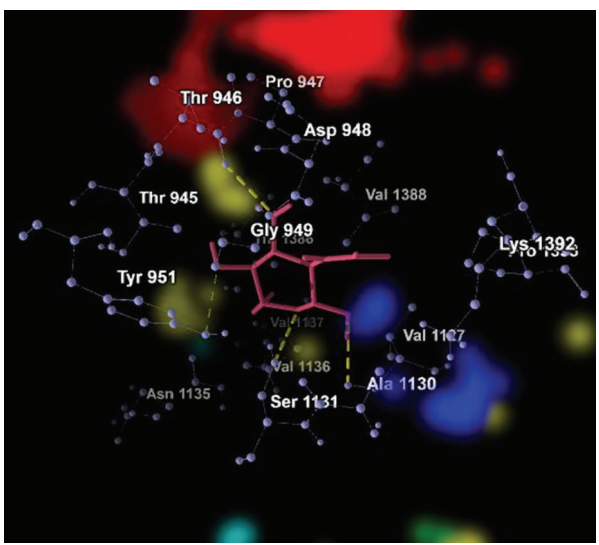

Figure 6: Binding of N-acetyl-D-glucosamine with PAI1.

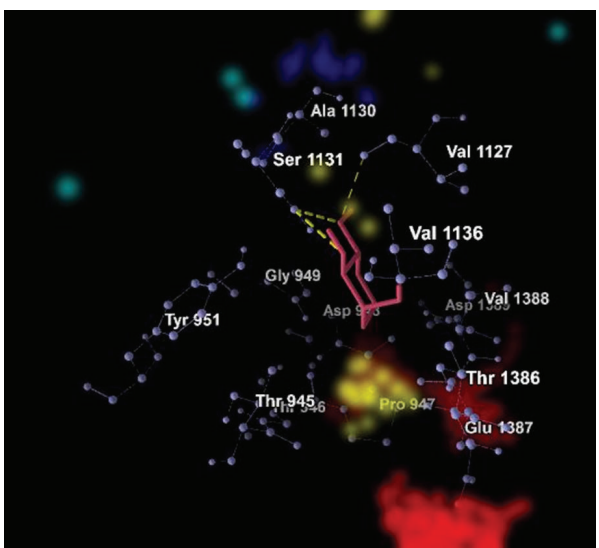

FIGURE 7: Binding of ribose with PAIl. 


\section{Conflict of Interests}

The authors declare that there is no conflict of interests regarding the publication of this paper.

\section{References}

[1] J. W. Y. Yau, S. L. Rogers, R. Kawasaki et al., "Global prevalence and major risk factors of diabetic retinopathy," Diabetes Care, vol. 35, no. 3, pp. 556-564, 2012.

[2] K. P. Sampath kumar, D. Bhowmik, G. Harish, S. Duraivel, and B. Pragathi kumar, "Diabetic retinopathy-symptoms, causes, risk factors and treatment," The Forma Innovation, vol. 1, no. 8, pp. 7-13, 2012.

[3] T. Sakamoto, H. Yasue, H. Ogawa, I. Misumi, and T. Masuda, "Association of patency of the infarct-related coronary artery with plasma levels of plasminogen activator inhibitor activity in acute myocardial infarction," The American Journal of Cardiology, vol. 70, no. 3, pp. 271-276, 1992.

[4] K. Bajou, A. Noël, R. D. Gerard et al., "Absence of host plasminogen activator inhibitor 1 prevents cancer invasion and vascularization," Nature Medicine, vol. 4, no. 8, pp. 923-928, 1998.

[5] A. Basu, G. Menicucci, J. Maestas, A. Das, and P. McGuire, "Plasminogen activator inhibitor-1 (PAI-1) facilitates retinal angiogenesis in a model of oxygen-induced retinopathy," Investigative Ophthalmology \& Visual Science, vol. 50, no. 10, pp. 4974-4981, 2009.

[6] H. M. Berman, J. Westbrook, Z. Feng et al., "The protein data bank," Nucleic Acids Research, vol. 28, no. 1, pp. 235-242, 2000.

[7] K. P. Tan, R. Varadarajan, and M. S. Madhusudhan, "DEPTH: a web server to compute depth and predict small-molecule binding cavities in proteins," Nucleic Acids Research, vol. 39, no. 2, pp. W242-W248, 2011.

[8] D. S. Wishart, D. Tzur, C. Knox et al., "HMDB: the human metabolome database," Nucleic Acids Research, vol. 35, no. 1, pp. 521-526, 2007.

[9] D. S. Wishart, C. Knox, A. C. Guo et al., "DrugBank: a comprehensive resource for in silico drug discovery and exploration," Nucleic Acids Research, vol. 34, no. 1, pp. 668-672, 2006.

[10] M. Whirl-Carrillo, E. M. McDonagh, J. M. Hebert et al., "Pharmacogenomics knowledge for personalized medicine," Clinical Pharmacology \& Therapeutics, vol. 92, no. 4, pp. 414417, 2012.

[11] A. Chikhi and A. Benseguen, "Docking efficiency comparison of Surflex, a commercial package and Arguslab, a licensable freeware," Journal of Computer Science \& Systems Biology, vol. 1, pp. 81-86, 2008.

[12] D. Schneidman-Duhovny, Y. Inbar, R. Nussinov, and H. J. Wolfson, "PatchDock and SymmDock: servers for rigid and symmetric docking," Nucleic Acids Research, vol. 33, no. 2, pp. W363-W367, 2005. 

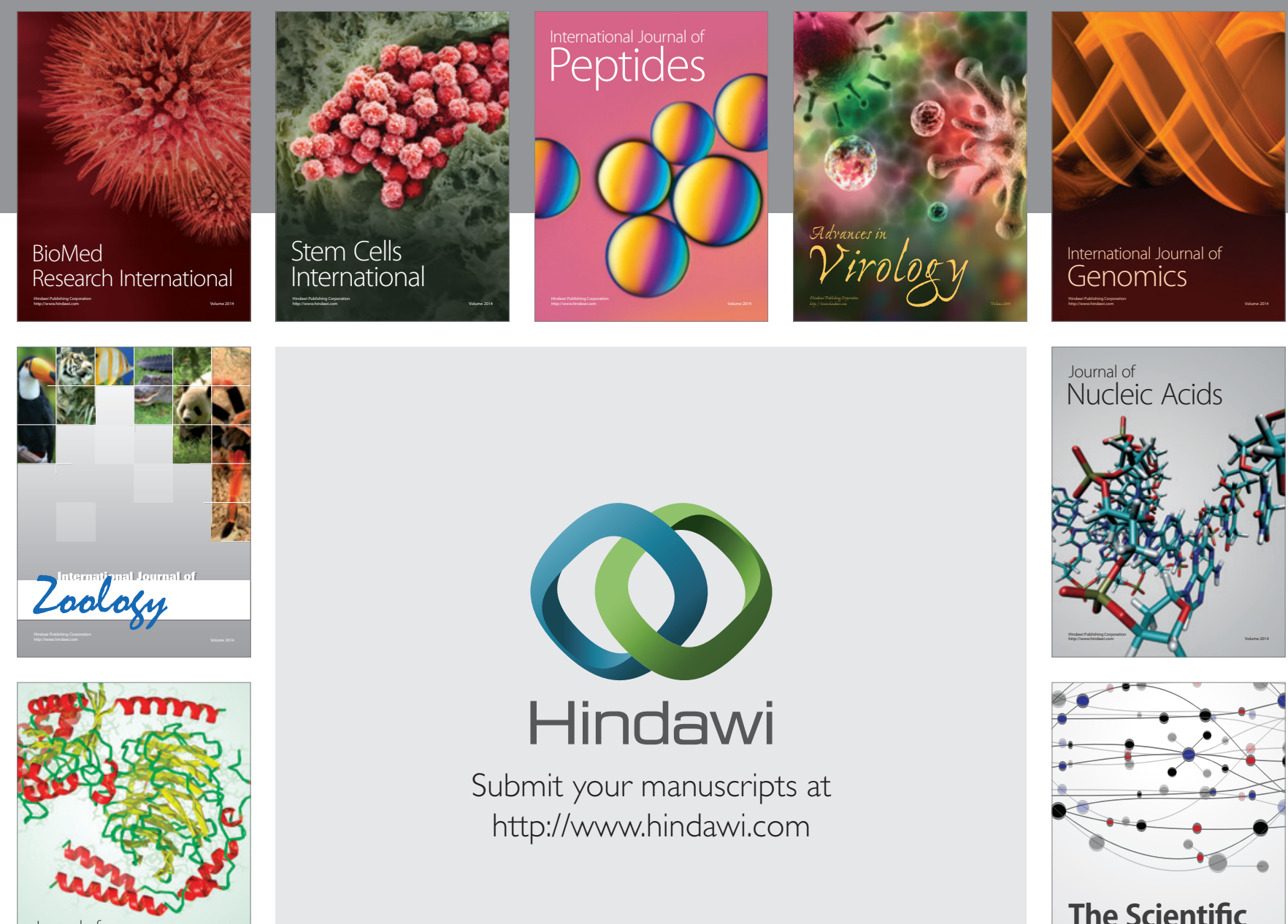

Submit your manuscripts at

http://www.hindawi.com

Journal of
Signal Transduction
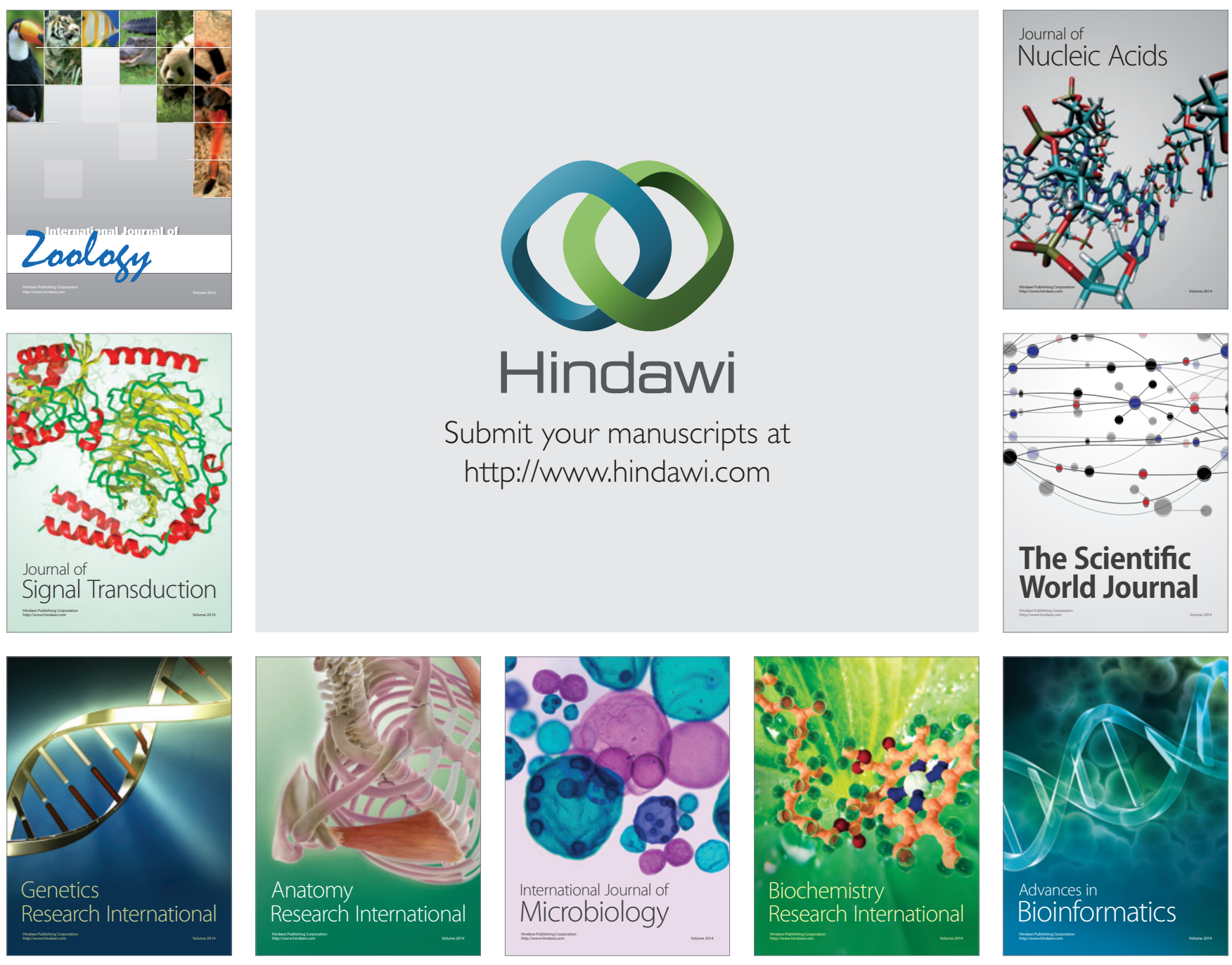

The Scientific World Journal
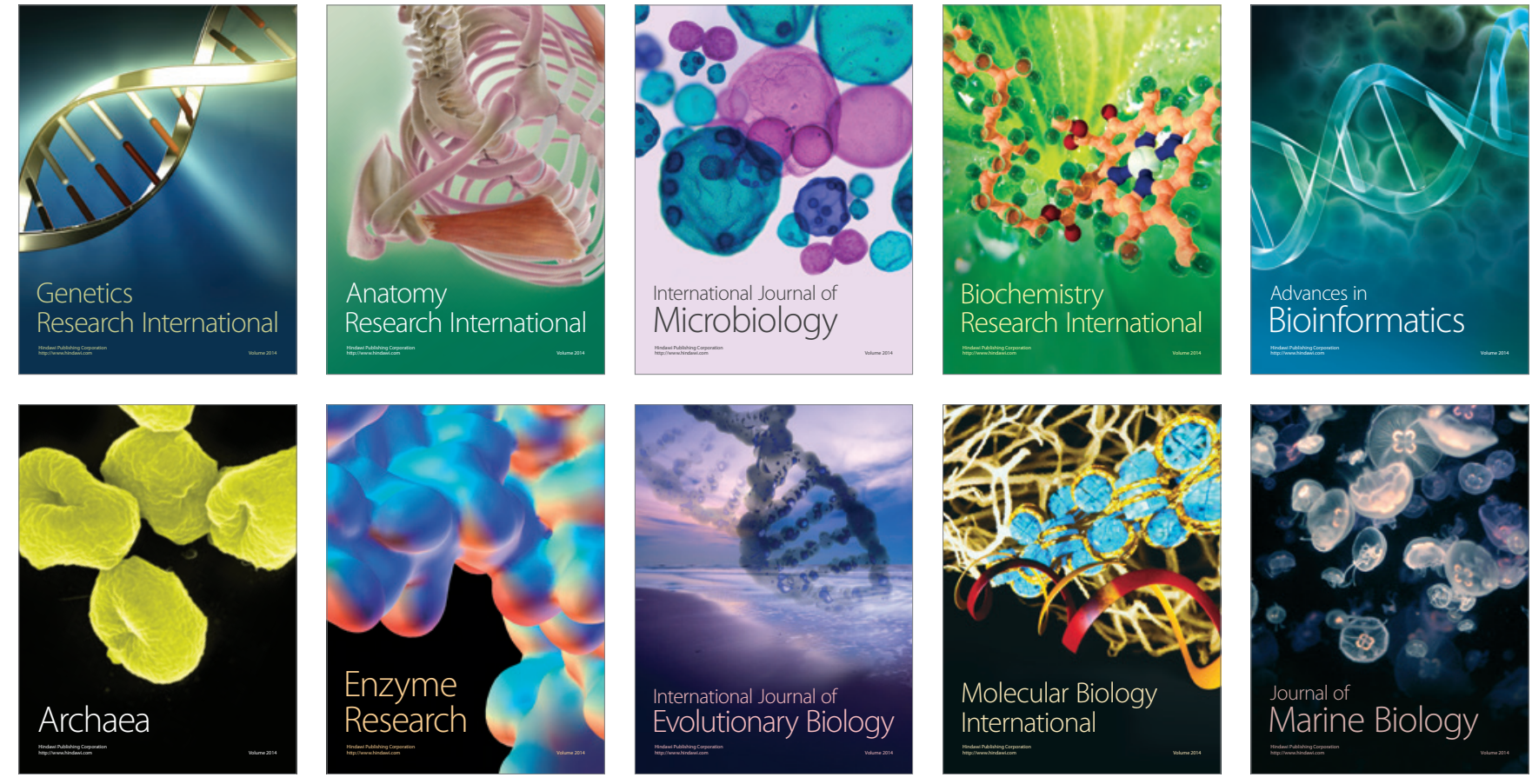